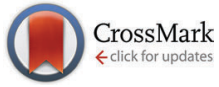

Cite this: Phys. Chem. Chem. Phys. 2014, 16, 25649

DOI: $10.1039 / c 4 c p 90161 d$

www.rsc.org/pccp

\section{Correction: Reactive simulations of the activation barrier to dissolution of amorphous silica in water}

\author{
Michael Kagan, Glenn K. Lockwood and Stephen H. Garofalini* \\ Correction for 'Reactive simulations of the activation barrier to dissolution of amorphous silica in water' \\ by Michael Kagan et al., Phys. Chem. Chem. Phys., 2014, 16, 9294-9301.
}

On page 9300, in the last sentence of the first paragraph of the Conclusions, the first data range is incorrectly shown as $18-24 \mathrm{kcal}_{\mathrm{mol}}{ }^{-1}$, instead of $14-24 \mathrm{kcal} \mathrm{mol}^{-1}$. The sentence should therefore read as follows:

This result is within the lower end of the experimental data, which varies from 14-24 kcal mol ${ }^{-1}$, while various $a b$ initio calculations using small cluster models obtain values that vary from $18-39 \mathrm{kcal} \mathrm{mol}^{-1}$.

The Royal Society of Chemistry apologises for these errors and any consequent inconvenience to authors and readers. 